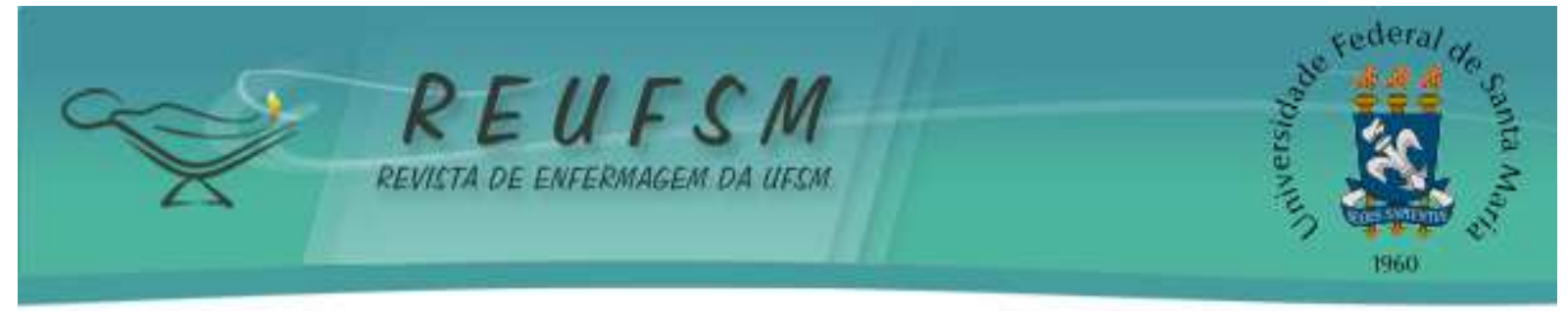

ARTIGO ORIGINAL

\title{
PERCEPÇÕES DOS PROFISSIONAIS DE ENFERMAGEM NA ASSISTÊNCIA A CRIANÇAS PORTADORAS DE CÂNCER
}

\section{PERCEPTION OF NURSING PROFESSIONALS IN ASSISTING CHILDREN WITH CANCER PERCEPCIONES DE LOS PROFESIONALES DE ENFERMERÍA EN LA ASISTENCIA A LOS NIÑOS PORTADORES DE CÁNCER}

Débora Maria Bastos Pereira ${ }^{1}$ Karine Bertoldi ${ }^{2}$ Adriana Roese ${ }^{3}$

Doi: $10.5902 / 2179769213426$

RESUMO: Objetivo: analisar a vivência da equipe de Enfermagem no cuidado à criança com câncer, em uma Unidade Pediátrica de um Hospital Universitário do Sul do Brasil. Método:trata-se de uma pesquisa de abordagem qualitativa, descritiva e exploratória. Os dados foram coletados por meio de entrevistas e a análise dos dados ocorreu por categorização temática. Resultados: observou-se que os profissionais apresentaram dificuldades no trabalho realizado junto à oncologia pediátrica devido a sua proximidade com sentimentos de dor, morte e sofrimento. Os profissionais manifestaram sentimentos variados em relação ao cuidar que foram do pesar ao não considerar diferenças em relação a outros pacientes pediátricos. Conclusão: existe a necessidade de apoio psicológico da instituição e de capacitação para melhor enfrentamento dos sentimentos que essa doença acarreta ao profissional e para a qualificação do cuidado junto às crianças e suas famílias.

Descritores: Criança hospitalizada; Relações profissional-paciente; Pediatria; Oncologia.

ABSTRACT: Aim: to analyze the experience of a nursing staff in the care of children with cancer in a Pediatric Unit of a University Hospital in southern Brazil. Method: it is a qualitative, descriptive and exploratory research. Data were collected through interviews and the analysis was carried out through thematic categorization. Results: it was observed that the professionals had difficulties in Pediatric Oncology work due to the approximation with feelings of pain, suffering and death. The professionals expressed various feelings in relation to the care, which ranged from sorrow to not considering differences in relation to other pediatric patients. Conclusion: it is necessary to provide the staff with psychological support and training programs so that they can better tackle with the feelings that the disease causes on professionals and to qualify the care of the children and their families.

Descriptors: Child, hospitalized; Professional-patient relations; Pediatrics; Medical oncology.

RESUMEN: Objetivo: analizar la vivencia del equipo de enfermería en el cuidado al niño con cáncer, en una unidad pediátrica de un hospital universitario del sur de Brasil. Metodo: estudio cualitativo, descriptivo y exploratorio. Los datos fueron recolectados por medio de entrevistas. El análisis de datos se realizó por categorización temática. Resultados: se observó que los profesionales presentaron dificultades en el trabajo junto

\footnotetext{
${ }^{1}$ Enfermeira graduada pela UFPel, Mestranda em Ciências Médicas da UFRGS, Rio Grande do Sul. Porto Alegre, RS, Brasil. E-mail: deborambp@gmail.com

${ }^{2}$ Enfermeira graduada pela UFRGS, Doutoranda em Ciências Biológicas: Fisiologia da UFRGS, Porto Alegre, RS, Brasil. E-mail: kakibertoldi@gmail.com

${ }^{3}$ Doutora em Enfermagem, Universidade Federal do Rio Grande do Sul. Docente do Curso de Saúde Coletiva, Universidade Federal do Rio Grande do Sul. Porto Alegre, RS, Brasil. E-mail: adiroese@gmail.com
} 


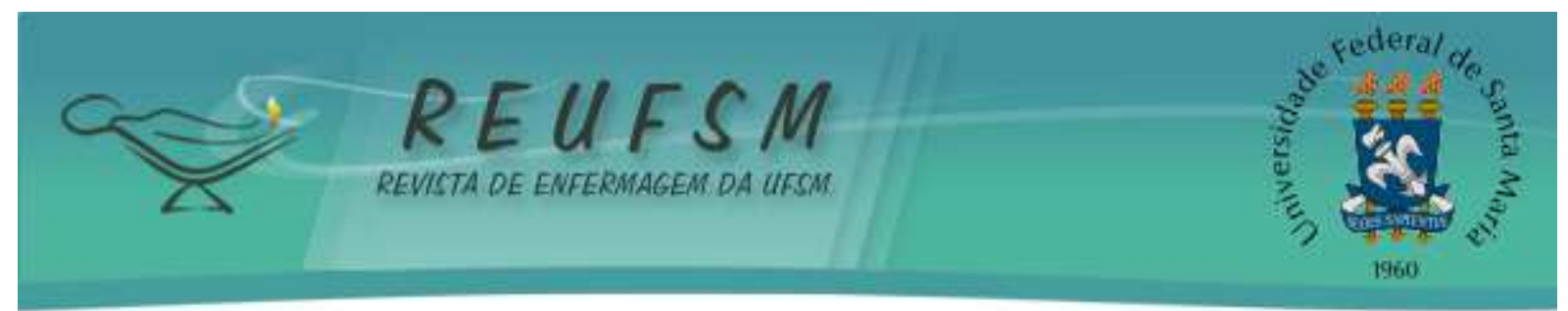

a la oncología pediátrica debido a su proximidad con sentimientos de dolor, muerte y sufrimiento. Los profesionales manifestaron sentimientos variados en relación al cuidado, que fueron del pesar al no considerar diferencias en relación a otros pacientes pediátricos. Conclusión: existe la necesidad de apoyo psicológico de la institución y de capacitación para enfrentar mejor los sentimientos que esa enfermedad acarrea al profesional y para la cualificación del cuidado junto a los niños y sus familias.

Descriptores: Niño hospitalizado; Relaciones profesional-paciente; Pediatría; Oncología médica.

\section{INTRODUÇÃO}

O câncer infantil é uma doença que resulta da proliferação desordenada de células podendo ocorrer em qualquer órgão. Os sintomas são inespecíficos e muitas vezes semelhantes aos de outras doenças. ${ }^{1}$ Segundo o Instituto Nacional de Câncer (INCA), no Brasil, em 2011, ocorreram 2.812 óbitos por câncer em crianças e adolescentes (de 0 a 19 anos). Além disso, as neoplasias são consideradas as doenças mais letais, uma vez que ocupam a segunda posição (7\%) de óbitos dessa faixa etária (de 0 a 19 anos), perdendo apenas para óbitos por causas externas. ${ }^{2}$ Estima-se que no ano de 2014 sejam registrados mais de 394.450 novos casos de câncer, sendo que entre estes, 11.840 afetarão crianças e jovens com até 19 anos. ${ }^{2}$

Especificamente no Rio Grande do Sul surgem, anualmente, cerca de 300 novos casos de câncer em crianças e adolescentes de 0 a 19 anos. Em relação ao câncer infantil, o índice de cura é em torno de $70 \%$, no entanto, nos tipos mais graves esse índice diminui para apenas $20 \%{ }^{3-4}$

$\mathrm{Na}$ maioria dos casos de tumores infantis um diagnóstico precoce é difícil de ser alcançado, pois a progressão da doença é silenciosa e os sinais e sintomas tendem a aparecer somente com o avanço da doença. Diversos fatores podem estar relacionados ao diagnóstico tardio como a falta de informação dos pais e médicos, medo do diagnóstico de câncer ou até mesmo as próprias características do tumor. ${ }^{4}$

A partir da realização do diagnóstico e início do tratamento ocorrem diversas alterações na vida da criança portadora de câncer e da sua família. Após a chegada da criança ao hospital um dos elementos fundamentais é estabelecer um relacionamento seguro, tranquilo e de empatia com a equipe multidisciplinar, minimizando assim os efeitos nocivos causados pelo ambiente de internação. Ainda, a presença de uma criança portadora de câncer afeta as dimensões externas à sua estrutura familiar exigindo reflexões e adaptações tanto por parte da criança quanto dos seus familiares. ${ }^{5}$

Nesse contexto, o suporte da equipe de enfermagem através do fornecimento de informações e orientações desde a chegada do paciente e durante a sua permanência no hospital é extremamente importante. ${ }^{6}$ Além disso, é fundamental observar as reações dos pais frente às diferentes situações e permitir que eles expressem suas dúvidas e suas ansiedades relacionadas à doença. ${ }^{7}$

O cuidado realizado na área da saúde é um processo interativo onde existe uma troca de experiências entre o profissional, o paciente e seus familiares. Dessa forma, o cuidado ultrapassa a barreira do conhecimento científico, do simples ato simbólico ou procedimento técnico e exige que o profissional da saúde relacione a sensibilidade ao conhecimento teórico com a finalidade de oferecer uma assistência qualificada e humanizada. ${ }^{8-9}$

A inserção da equipe de enfermagem no cuidado ao paciente oncológico requer conhecimentos, habilidades e responsabilidades. Nesse sentido, as metas devem ser claras e direcionadas ao paciente, sua família e amigos dos pacientes, contemplando os aspectos físico, emocional, social e espiritual. Dessa forma, existe a necessidade de um maior 


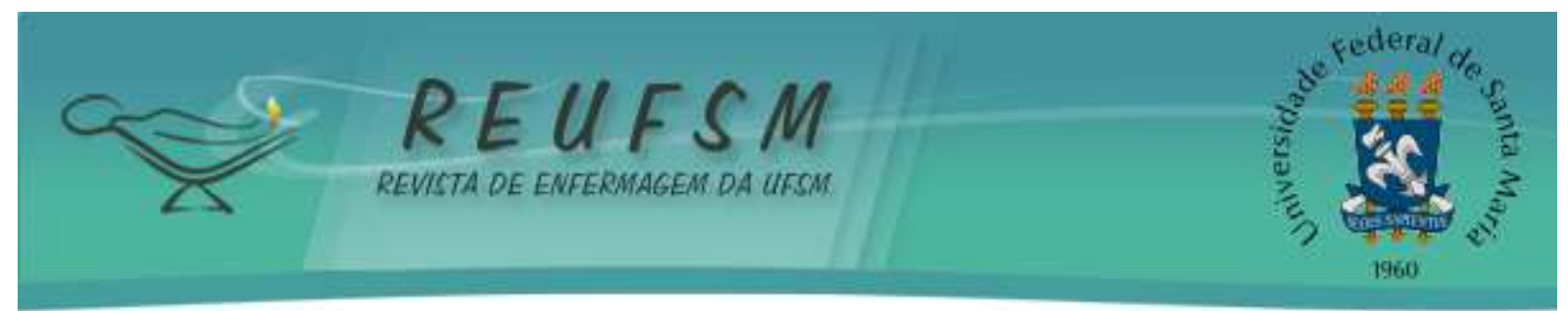

preparo da equipe relacionado tanto às rotinas de cuidados ao paciente quanto à atenção aos fatores psicológicos do enfermo, da família e de si mesmo. ${ }^{10}$

A relação de proximidade estabelecida entre o profissional de enfermagem e o paciente por um período de tempo prolongado acaba proporcionando, ao cuidador, sentimentos como impotência diante da doença, descrença em relação às medidas terapêuticas e expectativa de morte como uma possibilidade. ${ }^{11}$ Por esse motivo, os profissionais precisam estar devidamente preparados para lidar com situações e sentimentos que são comumente vivenciados nessa área. ${ }^{12}$

Atualmente, existem poucos estudos abordando os sentimentos e percepções dos profissionais de enfermagem em relação ao cuidado da criança com câncer. O presente trabalho buscou analisar a vivência da equipe de Enfermagem no cuidado à criança com câncer em uma Unidade Pediátrica de um Hospital Universitário do Sul do Brasil.

\section{MÉTODO}

O presente estudo é do tipo descritivo e exploratório, com abordagem qualitativa. $^{13}$ A pesquisa foi desenvolvida na Unidade Pediátrica em um hospital universitário do Sul do Brasil. As entrevistas semiestruturadas foram realizadas junto aos sujeitos escolhidos (por meio de sorteio), sendo eles a enfermeira de cada turno e um funcionário por categoria profissional (nível auxiliar, técnico e superior), em cada turno (manhã, tarde e noite), e nas cinco equipes, totalizando 10 participantes durante o mês de setembro de 2011. Pensa-se que o número de 10 participantes tenha sido suficiente para atingir a saturação dos dados, uma vez que, em pesquisa qualitativa, o critério da amostra não é numérico, embora a delimitação dos entrevistados seja necessária. ${ }^{13}$

A pesquisa foi realizada em um setor de assistência pediátrica geral e os entrevistados foram selecionados através de sorteio. No caso de o sorteado não ter atendido pacientes oncológicos a pesquisadora entrevistou o sorteado reserva. As entrevistas foram realizadas individualmente em um local disponível na unidade em horário anteriormente agendado e com duração de, aproximadamente, 15 minutos. As respostas foram gravadas em MP3 e posteriormente transcritas na íntegra. 0 roteiro da entrevista foi composto pelas seguintes questões: Que percepções lhes são manifestadas ao assistir crianças portadoras de câncer? Você realiza/presta cuidados diferenciados a esta criança e família? Como é a sua relação com o familiar/cuidador da criança com câncer?

A fim de manter o anonimato, os participantes do estudo tiveram seu nome trocado por números de acordo com a ordem da entrevista e mediante assinatura do termo de consentimento livre e esclarecido. Os princípios éticos foram respeitados conforme a Resolução 196/1996, do Conselho Nacional de Saúde, em vigor no período da pesquisa. ${ }^{14}$ A realização do estudo foi autorizada pela instituição e aprovada pelo Comitê de Ética da Faculdade de Enfermagem/UFPel, sob o número 052/2011.

Após a leitura das respostas e análise dos dados uma categorização foi realizada gerando as seguintes temáticas: 1) Sentimentos da equipe em relação ao processo de cuidar crianças com câncer, 2) Cuidado diferenciado aos pacientes pediátricos oncológicos e 3) Sentimentos da equipe em relação aos familiares de crianças com câncer. ${ }^{15,16}$

\section{RESULTADOS E DISCUSSÃO}

O perfil ilustrativo dos entrevistados demonstra que todos eram representantes do sexo feminino, no entanto haviam funcionários do sexo masculino no setor onde a pesquisa foi realizada. A idade das profissionais oscilou entre 39 e 67 anos e o tempo de atuação no 


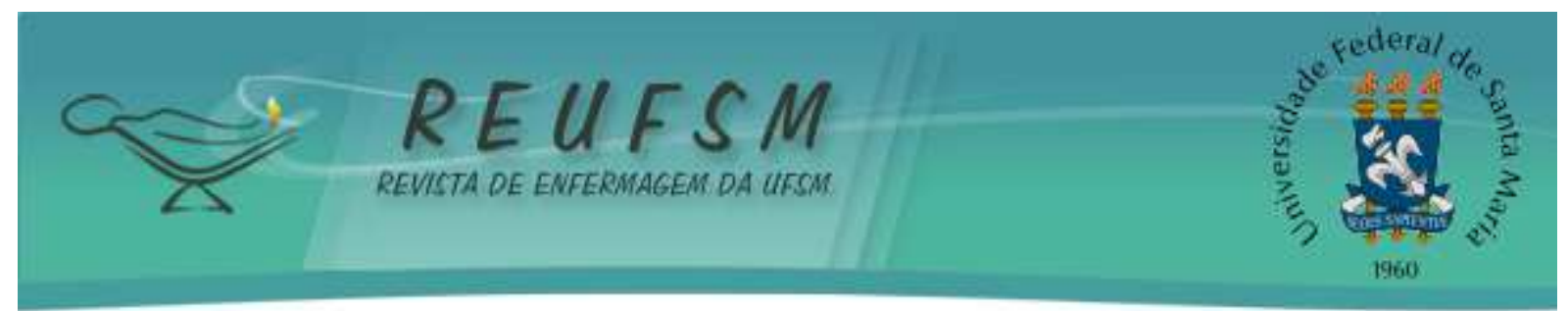

serviço variou de 02 a 24 anos. Este dado pode justificar, pelo menos em parte, a diversidade de vivências e opiniões das participantes do presente estudo.

\section{Sentimentos da equipe em relação ao processo de cuidar crianças com câncer}

O câncer, geralmente, é visto como sinônimo de dor, morte e sofrimento. 0 diagnóstico de câncer pode ser respondido de diversas formas em diferentes indivíduos, porém reações como medo, ansiedade, negação, desesperança e perda de controle geralmente são sentimentos comuns.

A atuação da equipe tem como desafio proporcionar ao paciente uma experiência com outra gama de sentimentos, tais como: o amor, o alívio, a serenidade e a alegria em relação ao tratamento. A interdisciplinaridade do cuidado à saúde surge como possibilidade de novas alianças, difíceis, mas que trará criatividade e avanço para o tratamento do paciente oncológico. ${ }^{17}$

Neste cenário a equipe de saúde, especialmente a de Enfermagem, necessita estar apta a prestar atendimento humanizado, compreendendo e apoiando o paciente e seus familiares em todas as suas necessidades ao longo do processo do adoecimento. ${ }^{18,19}$

Neste tema os sentimentos da equipe de enfermagem que trabalha no cuidado à criança com câncer são relatados. A análise demonstrou que a maioria dos profissionais que assistiam crianças portadoras de câncer há muitos anos, não gostavam de lidar ou, sentiam-se tristes com esse tipo de paciente. Observou-se que a convivência diária com pacientes oncológicos e também com a perda são fatores que poderiam levar à depressão como mencionado pela entrevistada 1.

Eu sou uma pessoa que não gosto de cuidar, não gosto. Acho muito deprimente, cuido porque tem pacientes no serviço e não tem como [...]. (E1)

Vários tipos de sentimentos em relação a esse cuidado foram observados, geralmente, sentimentos tristes como relatados pelas entrevistadas 4 e 7 , inclusive trazendo elementos sociais para justificar a doença.

Tu não deixas de teres pena, não é! (E4)

Ah, a primeira coisa que a gente sente é pena, não é! [...] porque aceitar a gente não aceita nunca, mas adulto pelo menos já teve uma vivência [...] Aí a gente conversa com a família, ai começa a perguntar: "a senhora trabalha aonde? ah, na lavoura?" Aí ela começa a falar "ah, trabalhava pra fora no fumo, aí o marido também aí ela ia grávida, com a criança pra lavoura também, sabe?! Aí a gente vai começando a juntar sabe!? [...] sei lá, sempre pra tentar justificar [...] não é pra aceitar, mas pelo menos pra tentar entender. É pra não ficar tão triste assim. (E7)

Além disso, algumas entrevistadas sentiam dificuldades em falar sobre seus sentimentos relacionados ao cuidado da criança com câncer como observado na resposta da entrevistada 8. No entanto, ela expressou sua preocupação em relação ao tratamento e a esperança de uma resposta positiva da criança ao mesmo, como demonstrado abaixo. 


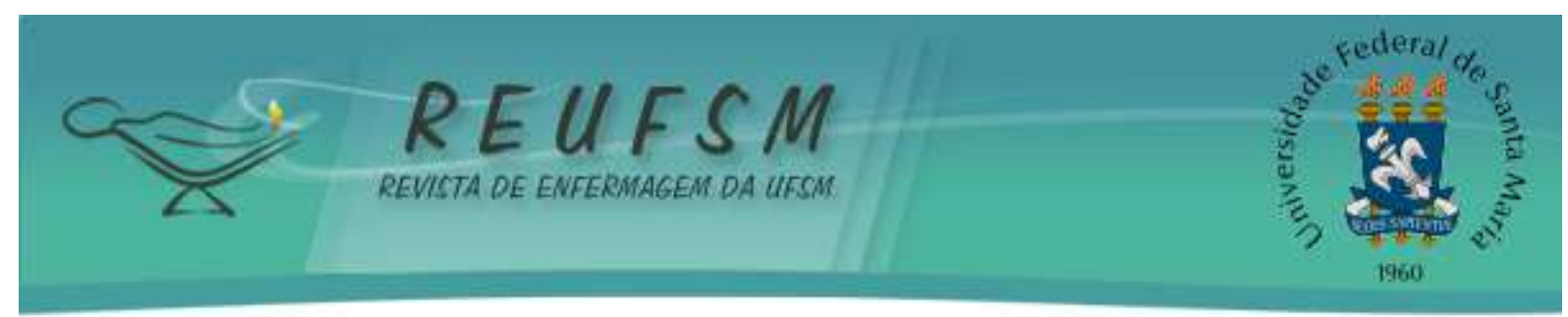

É a preocupação nossa maior é pelo tratamento, pelas dificuldades do tratamento e a questão da criança receber o tratamento, a sintomatologia que ela fica, né!? E sobre a sensação que essa doença vá evoluir bem, né?! [...] porque o tratamento pode surtir efeito, é essa a nossa maior preocupação, né?! Então, como é que mesmo o nome da pergunta? (E8)

Ainda, a entrevistada 9 também mencionou a sua preocupação com o tratamento no entanto, ao contrário da entrevistada 8 , ela expressou seus receios em relação ao mau prognóstico quando o tratamento não é eficaz. Além disso, relatou a necessidade do paciente procurar centros mais avançados, uma vez que, muitos centros hospitalares não possuem a estrutura necessária para proporcionar um tratamento efetivo.

[...] E a decepção no momento da resposta positiva, do tratamento [...] E também, muitas vezes, nós nos angustiamos porque a gente sabe que não tem o tratamento ideal com relação ao diagnóstico assim que talvez essa criança seria bem melhor atendida num outro centro mais avançado, por exemplo Porto Alegre e ela acaba ficando aqui por falta de condições financeiras, de encaminhamento ou por falta de esclarecimento até da família, né!? (E9)

A entrevistada (E5) relatou ainda que quando tinha oportunidade procurava não atender crianças com câncer que internavam na unidade.

[...] Quando tem criança com câncer aqui no isolamento eu procuro nem entrar, é que a minha enfermaria é de pneumologia [...] então ali eu estou sempre envolvida, sempre. (E5)

A equipe demonstra em suas falas a falta de preparo emocional para lidar com esse tipo específico de pacientes. O despreparo dos profissionais para lidar com os sentimentos do paciente e do familiar gera um ciclo vicioso de alterações emocionais, interferindo posteriormente em sua atuação técnica. Esse ciclo deve ser interrompido para melhorar a assistência psico-espiritual do paciente e prevenir um desgaste da equipe de saúde, aumentando sua eficiência e produtividade. ${ }^{20}$

\section{Cuidado diferenciado aos pacientes pediátricos oncológicos}

A oncologia pediátrica é uma das áreas mais relacionadas à dor, sofrimento, ansiedade e estresse à equipe de enfermagem, portanto é necessário considerar como essa equipe sente-se frente à criança oncológica e seus familiares, estando ela fora de possibilidades terapêuticas ou não. ${ }^{18}$

0 profissional de enfermagem, mesmo aquele que se dedicava ao cuidado em pediatria há muitos anos, revelou sentir dificuldades em lidar com as especificidades da oncologia pediátrica a qual pode ser justificada pela falta de preparo e amparo ao profissional da saúde. Desta forma, é de fundamental importância o apoio psicológico da instituição e a capacitação para melhor enfrentamento do pesar que essa doença acarreta ao profissional. ${ }^{12}$

As entrevistadas 10 e 6 foram questionadas sobre seus sentimentos em relação ao cuidado diferenciado prestado ao paciente oncológico, porém ambas negaram a prestação 


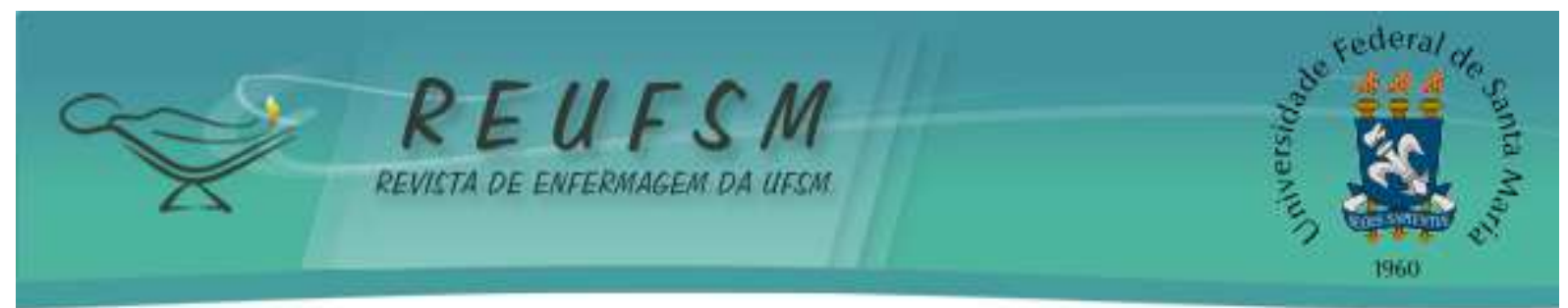

de cuidado diferenciado e afirmaram que o cuidado é o mesmo independente do paciente em questão.

Não, porque é um paciente como os outros, necessitam de todos os cuidados. (E10)

Eu não faço muita diferença entre aquela criança com câncer $e$ aquela que tem derrame pleural, uma pneumonia [...] até porque trabalhando em pediatria, em UTI é diferente, tem o "pode morrer", na pediatria tu já "pode controlar". Geralmente a gente se apega um pouco mais porque eu acho que tem que ter uma atenção a mais, mas, eu tento não fazer diferença [...] (E6)

Outra profissional (E5) referiu que não teria como responder a essa pergunta devido ao envolvimento, porém relatou que era diferente trabalhar com esse tipo de criança principalmente pela presença contínua da possibilidade da morte.

Ah, isso é uma coisa que não dá pra responder [...] é ruim, a gente se envolve muito, depois quando morre a gente sente muito, entendeu!? A gente se envolve muito com uma criança com câncer. [...] é diferente que os outros, entendeu!? (E5)

Assim pode-se observar que o cuidar de crianças em oncologia é complexo e pode acarretar muito sofrimento à equipe, visto que o enfermeiro, muitas vezes, não consegue lidar com a morte e o morrer como uma possibilidade do fim do ciclo da vida. ${ }^{7}$ Sendo assim, enquanto a criança se encontra em um momento de maior necessidade de cuidado e atenção, os profissionais nem sempre estão preparados para compartilhar esse momento tão difícil, demonstrando que prestar assistência à criança com câncer, principalmente sob cuidados paliativos, é um processo de sofrimento e um misto de emoções para o profissional. ${ }^{8}$

A entrevistada 3 gerou outro aspecto para discussão, pois relatou que devido às diversas internações ou períodos prolongados de internação o profissional acaba se relacionando com a família, assim cuidando não só da saúde física mas influenciando na parte psicológica também.

[...] e às vezes quando é bebê, uma criança que a relação, não é assim tão próxima tu acaba te afeiçoando mais a família, não é! Tu conversas mais, tu conheces mais um pouco da história daquela família porque tu tens tempo pra conversar sobre isso, não é! [...] te preocupar em conhecer mais a fundo [...] Diferente, não que a gente não tenha com os outros pacientes, mas é um pouco diferente assim esse vínculo, acho que por o vínculo ser maior a gente se afeiçoa mais, conversa outras coisas que a gente não conversaria com pacientes normal não é, pacientes que internam e dão alta e não voltam mais. (E3)

A comunicação entre o profissional, a família e o paciente pode permitir uma assistência de qualidade minimizando os medos e anseios provocados pela doença terminal e diminuindo os sintomas incapacitantes provocados pela doença. ${ }^{21}$

Uma pesquisa realizada com enfermeiros da oncologia pediátrica, de um hospital público brasileiro localizado na cidade de João Pessoa, PB, no período de abril a junho de 2010 demonstrou a importância da comunicação, seja ela verbal ou não com a criança que 


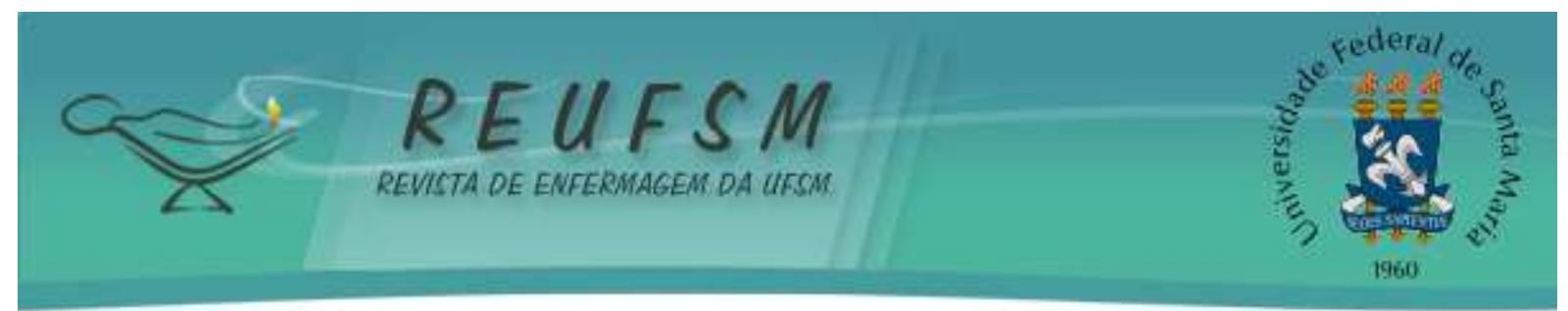

vivencia o processo da doença, e assim, pode-se considerar o alicerce de um bom relacionamento interpessoal, em busca do seu bem estar. ${ }^{21}$

Desta forma, é essencial que o enfermeiro tenha habilidade e sensibilidade, diante de suas próprias ações, para desenvolver o cuidado de modo interativo, estabelecendo relação pautada no encontro verdadeiro com as crianças e suas famílias que vivenciam o processo de finitude, em que a intencionalidade do agir e o conhecimento do que se espera de cada profissional, no processo de cuidar, sejam manifestos. ${ }^{22}$

\section{Sentimentos da equipe em relação aos familiares de crianças com câncer}

A presença do familiar durante o tratamento se faz indispensável devido ao impacto biopsicossocial que representa o câncer para a criança e sua família. Nesse sentido, a equipe de enfermagem pode proporcionar um atendimento humanizado e integral tanto para a criança quanto para a sua família, através de atividades lúdicas, medidas de conforto e de alívio dos sintomas físico-emocionais, entre outros. ${ }^{21} \mathrm{~A}$ abordagem à criança com câncer requer uma boa estrutura psicológica da equipe de enfermagem, pois estes profissionais são os responsáveis pelo cuidado técnico prestado à ela, além de fornecer suporte emocional para a família. ${ }^{22}$

A entrevistada 6 ressaltou que muitas vezes é a família quem necessitaria de mais cuidados:

[...] eu acho que a família é diferente, mas porque a criança mesmo não sabe o que vai acontecer com ela [...] acho que a família que precisa de mais atenção, a maioria das crianças com 2, 3, 4 anos, elas não tem lucidez pra saberem que vão morrer, não conseguirem controlar, tem um agora que está com quase oito que ele tinha, sabia bem o que ele tinha, sabia que era grave, sabia que podia morrer. (E6)

Já no depoimento da entrevistada 9 pode-se evidenciar que o sofrimento entre familiares e profissionais da saúde são divididos desde o momento de confirmação do diagnóstico estendendo-se durante todo o processo de adoecimento. A equipe evidencia em suas falas a preocupação com quem permanece ao lado da criança, passando por desgastes físicos e emocionais gerados pela doença e pelo ambiente hospitalar.

Então a gente passa por toda aquela angústia junto com a família, não é! [...] Da coleta dos exames, da realização de alguns exames, de aguardar o resultado [...] Aí então é sempre bem complicado pra toda equipe de enfermagem porque nós ficamos todo o tempo ali, não é! [...] Então, muitas vezes, a gente acaba trabalhando como psicóloga, como componente da família, é difícil diferenciar, não é! A parte emocional da profissional também. (E9)

A criança portadora de doença crônica estabelece um vínculo e uma familiaridade com o ambiente hospitalar devido às internações recorrentes além do tempo prolongado das internações. Além disso, outros fatores como a terapêutica agressiva com sérios efeitos indesejáveis advindos do próprio tratamento, dificuldades pela separação dos membros da família durante as internações, interrupção das atividades diárias, sofrimento e o medo constante da possibilidade de morte interferem na manutenção do bem estar do paciente e dos seus familiares. ${ }^{23}$ 


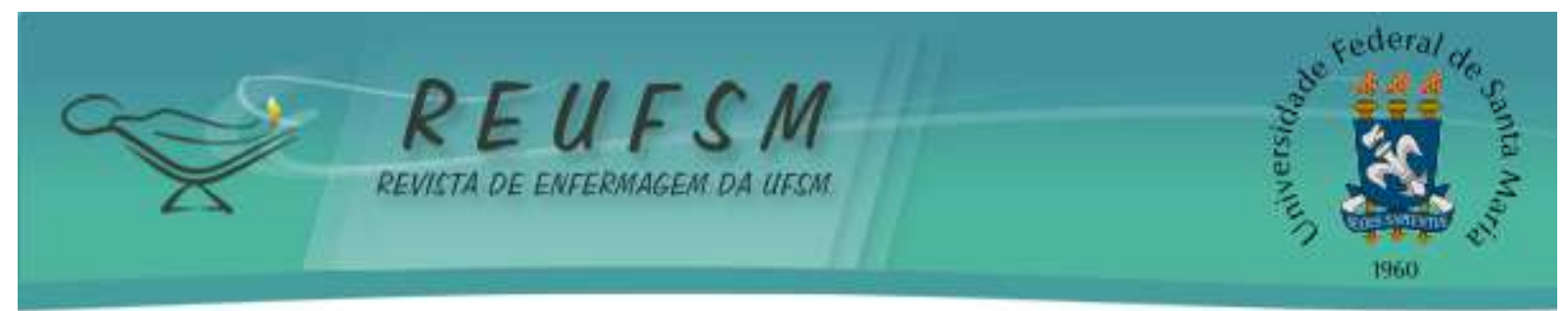

Como consequência, os profissionais que atuam nos serviços de saúde, desenvolvem vínculos e conhecem particularidades tanto da criança quanto da família, aprendendo assim a identificar as necessidades de ambos, prestando um cuidado diferenciado. ${ }^{20}$

0 cuidado é percebido como ação, vínculo, presença, sentimentos e promoção do desenvolvimento pessoal e espiritual. Diante do cotidiano assistencial percebem-se as limitações para enfrentar situações de estresse na busca da cura e no dilema da morte. 0 suporte emocional é imprescindível, no entanto isso ainda é uma lacuna na organização dos serviços de saúde. Somase a necessidade do preparo contínuo, tanto através de medidas educativas e aprimoramento de conhecimento técnico-teórico, quanto da atenção aos aspectos das relações humanas. ${ }^{15,20}$

\section{CONSIDERAÇÕES FINAIS}

Ao analisar a vivência de uma equipe de Enfermagem no cuidado à criança com câncer em uma unidade pediátrica, foi possível observar uma diversidade de sentimentos. Alguns profissionais se mostraram mais sensíveis ao sofrimento da criança e da família, enquanto outros relataram não haver diferença no cuidado às demais crianças da unidade. Essa situação refletiu sofrimento no cotidiano de trabalho e a necessidade de busca por estratégias para trabalhar seus sentimentos e, desta forma, prevenir o processo de exaustão, ansiedade, preocupações, angústias e medo.

Conclui-se que, existe a necessidade de apoio psicológico e capacitação da instituição aos profissionais da oncologia, para a qualificação do cuidado junto às crianças e suas famílias e para o melhor enfrentamento dos sentimentos em relação ao paciente oncológico pediátrico. Pretende-se que a divulgação do estudo possa contribuir com o trabalho dos profissionais da área junto a estes pacientes.

\section{REFERÊNCIAS}

1. Boldrini. Centro Infantil [Internet]. [acesso em 2011 maio 15]. Disponível em: http://www.boldrini.org.br/site/cancer_txt1.htm.

2. Brasil. Instituto Nacional de Câncer (INCA). Estimativas 2014: incidência de câncer no Brasil. [Internet]. [acesso em 2014 abr 23]. Disponível em: http://www.inca.gov.br/estimativa/2014/estimativa-24042014.pdf.

3. Brasil. Instituto Nacional de Câncer (INCA). Expectativa de novos casos de câncer para 2008 [Internet]. [acesso em 2011 maio 23]. Disponível em: http://www.inca.gov.br/expectativa .

4. Brasil. Instituto Nacional de Câncer (INCA). Particularidades do câncer infantil [Internet]. [acesso em 2011 abr 5]. Disponível em: http: //www.inca.gov.br.

5. Nascimento LC, Rocha SMM, Hayes VH, Lima RAG. Crianças com câncer e suas famílias. Rev Esc Enferm USP. 2005;39(4):469-74.

6. Groot-Bollüjt W, Mourik M. Bereavement: role of the nurse in the care of terminally ill and dying children in the pediatric intensive are unit. Rev Crit Care Med. 1993;21(9 Suppl):391-2.

7. Avanci BS, Carolindo FM, Goes FGB, Cruz Netto NP. Cuidados paliativos à criança oncológica na situação do viver/morrer: a ótica do cuidar em enfermagem. Esc Anna Nery Rev Enferm. 2009;13(4):708-16.

8. Duarte MLC, Zanini LN, Nedel MNB. O cotidiano dos pais de crianças com câncer e hospitalizadas. Rev Gaúch Enferm. 2012;33(3):111-8. 


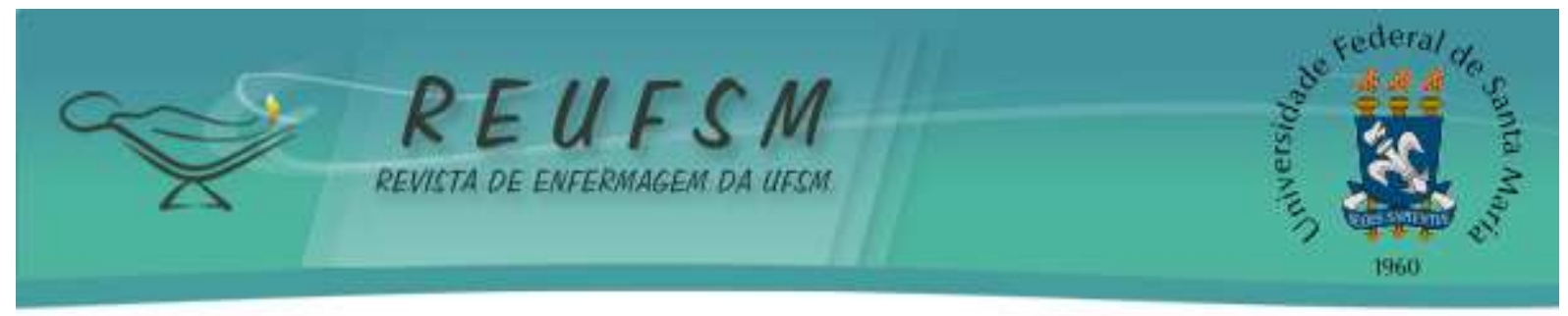

9. Celich KLS. Dimensões do processo de cuidar: a visão das enfermeiras. Rio de Janeiro: EPUB; 2004.

10. Stumm EMF, Leite MT, Maschio G. Vivências de uma equipe de enfermagem no cuidado a pacientes com câncer. Cogitare Enferm. 2008;13(1):75-82.

11. Avellar LZ, Iglesias A, Valverde PF. Sofrimento psíquico em trabalhadores de enfermagem de uma unidade de oncologia.Psicol Estud. 2007;12(3):475-81.

12. Ramalho MAN, Nogueira-Martins MCF. Vivências de profissionais de saúde da área de oncologia pediátrica. Psicol Estud. 2007;12(1):123-32.

13. Minayo MCS. O desafio do conhecimento: pesquisa qualitativa em saúde. $12^{\mathrm{a}}$ ed. São Paulo: Hucitec; 2010.

14. Brasil. Ministério da Saúde. Conselho Nacional de Saúde. Resolução CNS n 196 , de 10 de outubro de 1996. Dispõe sobre as diretrizes e normas regulamentadoras de pesquisa envolvendo seres humanos. Brasília (DF); 1996.

15. Oliveira ME, Fenili RM, Zampieri MF, Martins CR. Um ensaio sobre a comunicação no cuidado de enfermagem utilizando os sentidos. Enfermería Global [Internet]. 2006;(8):1-7. Disponivel em: http: //revistas.um.es/eglobal/issue/view/63/.

16. Silva RCF, Hortale VA. Cuidados paliativos oncológicos: elementos para o debate de diretrizes nessa área. Cad Saúde Pública. 2006;22(10):2055-66.

17. Silva LMH, Zago MMF. Cuidado do paciente oncológico com dor crônica na ótica do enfermeiro. Rev Latinoam Enferm. 2001;9(4):44-9.

18. Lemos FA, Lima RAG, Mello DF. Assistência à criança e ao adolescente com câncer: a fase da quimioterapia intratecal. Rev Latinoam Enferm. 2004;12(3):485-93.

19. Melo LL, Valle ERM. Equipe de enfermagem: experiência do cuidar de criança com câncer nos plantões noturnos. Rev Esc Enferm USP. 1998;32(4):325-34.

20. Fernandes MA, Evangelista CB, Platel ICS, Agra G, Lopes MS, Rodrigues FA. Percepção dos enfermeiros sobre o significado dos cuidados paliativos em pacientes com câncer terminal. Ciênc Saúde Coletiva. 2013;18(9):2589-96.

21. França JRFS, Costa SFG, Lopes MEL, Nóbrega MML, França ISX. Importância da comunicação nos cuidados paliativos em oncologia pediátrica: enfoque na Teoria Humanística de Enfermagem. Rev Latinoam Enferm. 2013;21(3):780-6.

22. Paro D, Paro J, Ferreira DLM. O enfermeiro e o cuidar em oncologia pediátrica. Arq Ciênc Saúde. 2005;12(3):151-7.

23. Nascimento LC, Rocha SMM, Hayes VH, Lima RAG. Crianças com câncer e suas famílias. Rev Esc Enferm USP. 2005;39(4):469-74.

Data de recebimento: $12 / 04 / 2014$

Data de aceite: 23/02/2015

Contato com autor responsável: Débora Maria Bastos Pereira

Endereço postal: Rua São Manoel, 963 - Campus da Saúde CEP: 90.620-110 - Porto Alegre RS - Brasil

E-mail: deborambp@gmail.com 